\title{
Structural changes of cellulosic polysaccharides in sesame hull during roasting
}

\section{at various temperatures}

\author{
Yong-Gang Yao ${ }^{1 \#}$, Wen-Yue Wang ${ }^{2 *}$, Li-Yan Chen ${ }^{1}$, Hua-Min Liu ${ }^{1 *}$, Rui-Zhe Yan ${ }^{1}$, Shan Li ${ }^{1}$, Xue-De Wang ${ }^{1 *}$ \\ ${ }^{1}$ College of Food Science and Engineering, Henan University of Technology, Zhengzhou, P. R. China; ${ }^{2}$ School of Life Sciences, \\ Zhengzhou University, Zhengzhou, China \\ \# These authors contributed equally to this work.
}

"Corresponding authors: Hua-Min Liu and Xue-De Wang, College of Food Science and Engineering, Henan University of Technology, NO.100, Lianhua Street, Zhengzhou, 450001, P. R. China. E-mails: liuhuamin5108@163.com; wangxuede1962@126.com.

Submitted: 6 January 2021; Accepted: 30 January 2021; Published: 1 April 2021

(C) 2021 Codon Publications

OPEN ACCESS (C) (i) () ()

RESEARCH ARTICLE

\begin{abstract}
This article reports a study of the degradation of roasted sesame hulls cellulosic polysaccharides contribution to the Maillard and caramelization reaction. In the present study, cellulosic polysaccharides were extracted from sesame hulls before and after roasting at various temperatures $\left(160,180,200\right.$, and $\left.220{ }^{\circ} \mathrm{C}\right)$. The structural variations of the cellulosic polysaccharides were elucidated by using the techniques: scanning electron microscope (SEM), high-performance anion-exchange chromatography, Fourier transform (FT-IR) spectrometer, carbon-13 nuclear magnetic resonance (CP/MAS $\left.{ }^{13} \mathrm{C}-\mathrm{NMR}\right)$, and thermal gravimetric analysis. The pyrolysis-gas chromatography-mass spectrometry (Py-GC/MS) characterized and verified the chemical composition obtained from the polysaccharide degradation during roasting. The sugar analysis results showed that galacturonic acid, xylose, and rhamnose were more easily degraded than arabinose, galactose, glucose, and mannose. The morphology of the cellulosic polysaccharides shows irregular dispersed globular fragments after roasting by SEM observation. FT-IR and CP/MAS ${ }^{13} \mathrm{C}-\mathrm{NMR}$ spectra indicated the crystalline structure and linkages of the cellulose did not break down in comparison to amorphous cellulose that partly degraded. Abundant acetic acid and 3-furaldehyde were among the polysaccharide degradation products identified by Py-GC/MS. These chemical compounds were likely the significant contributors to caramelization and the Maillard reaction in sesame seed roasting.
\end{abstract}

Keywords: cellulosic polysaccharides; sesame hull; roasting; structural characterization

\section{Introduction}

Sesame (Sesamum indicum L.) is an important food crop whose seeds are used for oil production (Elleuch et al., 2007; Lee et al., 2010). Roasting the seeds improves the color, flavor, and texture of the oil, ultimately promoting its overall palatability (Kahyaoglu and Kaya, 2006). Roasting is a high-temperature process that induces several complex chemical reactions, including stretcher degradation, the Maillard reaction, caramelization, and lipid oxidation (Parker, 2015). The Maillard reaction and caramelization are the more significant chemical reactions involving sugars responsible for the changes in odor, flavor, and the increase of antioxidant activity of the finished oil (Liu et al., 2020). During roasting, the Maillard reaction intermediate products, such as Amadori and Heyns compound, were subject to the type of sugar present (aldose and ketose sugar) (Brands and Van Boekel, 
2001). It is also reported that the Maillard reaction products (MRPs) color, antioxidative activity, and flavor were subject to the roasting temperature and time (Coghe et al., 2012; Magorzata et al., 2016).

The Maillard reaction is the chemical interactions between carbonyl compounds in carbohydrates and nucleophilic amino compounds like amino acids, peptides, or proteins that give browned food its distinctive flavor during roasting (Hwang et al., 2011). Caramelization is another critical non-enzymatic browning reaction in the sesame seed roasting process. The reaction starts with the thermal degradation of carbohydrates and contributes to the formation of both non-volatile and volatile products associated with color and flavor (Zhang et al., 2013). In roasting sesame seeds, temperatures of $200-240^{\circ} \mathrm{C}$ are applied, and the carbohydrates present in the seeds are degraded, providing carbonyl groups and sugars for caramelization and the Maillard reaction. Thus, investigating carbohydrate degradation can provide important information about the mechanisms that aid in color, flavor, and antioxidant product formation during roasting. The hulls of sesame seeds constitute approximately $12 \%$ of their total weight. The most pivotal carbohydrate components (cellulose and hemicelluloses) of the sesame seeds are found in the hulls (Farran et al., 2000). The most abundant polysaccharide in the sesame hulls is $47 \%$ cellulose, which consists of a linear polymer of $\beta-1,4$ linked glucopyranose units. There are crystalline and amorphous regions in cellulose (Nandi et al., 2018). The amorphous region has a comparatively low thermal stability, can be easily degraded into oligosaccharides at a low temperature than the crystalline regions (Matsuoka et al., 2014). Cellulosic polysaccharides degradation is strongly associated with the changes of color and flavor in the roasted oil. Hence, the study of roasting-induced modifications in structural properties of cellulose is critical.

Hydrogen bonds interconnect the hemicelluloses and cellulose in the sesame hulls (Liu et al., 2020). Research has shown that alkali extraction breaks hemicellulose by cleaving the ester linkages, covalent bonds, and the hydrogen bonds in the cell wall matrix and makes them soluble in an aqueous medium (Sun et al., 2013a). Therefore, in this study, sesame seed hulls were first roasted at different temperatures. Then they were extracted with alkali to remove the hemicelluloses, and later the cellulosic polysaccharides were separated. The structural features of cellulosic polysaccharides were comparatively investigated using scanning electron microscope, high-performance anion-exchange chromatography, Fourier transform spectrometer, carbon-13 nuclear magnetic resonance, thermal gravimetric analysis, and the pyrolysis-gas chromatography-mass spectrometry.

\section{Materials and methods}

\section{Reagents}

Sodium hydroxide $(\mathrm{NaOH})$, ethanol (95\%), toluene, sulfuric acid (98\%), and potassium bromide were purchased from Luoyang Chemical Co., Ltd (Luoyang, China). All reagents used in this investigation were of analytical grade.

\section{Materials and roasting process}

The white sesame seeds were provided by the Henan Academy of Agricultural Sciences. Sesame seed hulls were obtained from the sesame seeds by the dried de-hull method. The obtained hulls were dried at $60^{\circ} \mathrm{C}$ for $12 \mathrm{~h}$ and then stored in desiccators at room temperature for further analysis.

Firstly, for the roasting tests, $20 \mathrm{~g}$ of dried hulls were loaded in a $500 \mathrm{~mL}$ glass roaster and was heated in an oil bath at four different temperatures (160, 180, 200, and $220{ }^{\circ} \mathrm{C}$ ) for the desired holding time with continuous stirring using an IKA magnetic heating stirrer (IKA, Staufen, Germany). The samples roasted at various temperatures were named as RSH-160, RSH-180, RSH200 , and RSH-220, respectively and the un-roasted was labeled as USH. After the completion of each experiment the roasted hulls were removed and allowed to cool to room temperature. Later, the sesame hulls were treated with toluene-ethanol solution $(2: 1)$ to remove the wax and chlorophyll. Later, these hulls were finely milled and passed through a $1 \mathrm{~mm}$ mesh sieve. the resultant powders were stored in desiccators at room temperature for further cellulose isolation."

\section{Extraction of cellulosic polysaccharides}

The un-roasted and roasted powders were first extracted by $4 \% \mathrm{NaOH}(1: 20)$ in a $500 \mathrm{~mL}$ glass reactor for $5 \mathrm{~h}$ at $50^{\circ} \mathrm{C}$. Later, the solid fraction was separated by centrifuging at $4500 \mathrm{rpm}$ for $10 \mathrm{~min}$, washed with distilled water, and filtered until the filtrate was approximately neutral in $\mathrm{PH}$. The obtained residue was dried in an oven at $60^{\circ} \mathrm{C}$ for $12 \mathrm{~h}$. The residues rich in cellulose were as follows the unroasted sample (CR) and C160, C180, C200, and C220 for those roasted at the corresponding temperatures. To decrease the effect of other experimental operations on cellulose structure and to confirm the information about the cellulose degradation caused by roasting, the crude cellulose was not subject to further purification in the present study. Yields of the cellulosic polysaccharides were calculated on a dry weight basis relative to the starting un-roasted and roasted hulls. 


\section{Sugar analysis}

High-performance anion- exchange chromatography (HPAEC) was used to determine the monosaccharide compositions of the cellulosic fractions. Before analysis, the monosaccharides were hydrolyzed with $72 \%$ sulfuric acid at room temperature for $30 \mathrm{~min}$, followed by dilution to $1 \mathrm{M}$ at $105^{\circ} \mathrm{C}$ for $2.5 \mathrm{~h}$. Assuming hydrolysis was complete, the mixtures were filtered, and the aqueous solution was diluted 50 -fold. The solution was then analyzed on a Dionex ICS2500 chromatographic system (Thermo Scientific, Waltham, MA). The monosaccharides in the cellulosic preparations were determined by comparing retention times with standards.

\section{Fourier transform (FT-IR) spectrometer analysis}

FT-IR spectra of the residues were recorded on an IR spectrometer (Bruker-Vector 22, Billerica, MA) using a potassium bromide disk containing $1 \%$ finely ground samples, in the range $4000-400 \mathrm{~cm}^{-1}$. The spectra were obtained in absorption mode with a resolution of $2 \mathrm{~cm}^{-1}$ and an accumulation of 32 scans.

\section{Solid-state NMR measurement crystallinity index analysis}

The carbon-13 solid-state nuclear magnetic resonance (CP/MAS ${ }^{13} \mathrm{C}$-NMR) spectra were obtained on an MSL-300 spectrometer (Bruker operated at 75.5 $\mathrm{MHz}$ and the room temperature $\left(25^{\circ} \mathrm{C}\right)$. The proton $90^{\circ}$ pulse was $6 \mu \mathrm{s}$, the contact pulse $800 \mu \mathrm{s}$, rotation speed was $5 \mathrm{kHz}$, and the delay time after the signal acquisition was $2 \mathrm{~s}$. The crystallinity index (CrI) was calculated using the peak areas assigned to $\mathrm{C} 4$ crystallization (86-92 ppm) with the total area (81-92 ppm) in the $\mathrm{CP} / \mathrm{MAS}{ }^{13} \mathrm{C}$-NMR spectra. The cellulose $\mathrm{CrI}$ was determined from the peak areas assigned to $\mathrm{C} 4$ crystalline (86-92 ppm) and C4 noncrystalline (79-86 ppm) material.

\section{Thermal analysis}

The thermal properties of the cellulosic preparations were assessed using thermogravimetric analysis and differential thermal analysis (DTG) on a NetZSCH STA $449 \mathrm{C}$ instrument (Germany). Approximately $9-12 \mathrm{mg}$ of samples was accurately weighed and heated under nitrogen from $25-650{ }^{\circ} \mathrm{C}$ at a rate of $10^{\circ} \mathrm{C} / \mathrm{min}$.

\section{Pyrolysis-gas chromatography-mass spectrometry system (Py-GC/MS) analysis}

A Py-GC/MS was used to investigate the degradation product distribution of the cellulosic preparations. Prior to pyrolysis tests, $1 \mathrm{mg}$ of each cellulosic sample was loaded into a quartz tube and was pyrolyzed at $240^{\circ} \mathrm{C}$ under helium carrier gas for $30 \mathrm{~min}$. The evolved volatiles were separated by the coupled GC/MS, with the GC injector temperature set at $250{ }^{\circ} \mathrm{C}$. The oven temperature was programmed to hold at $50{ }^{\circ} \mathrm{C}$ for $1 \mathrm{~min}$. Later, it was increased from 50 to $240{ }^{\circ} \mathrm{C}$ at a rate of $5{ }^{\circ} \mathrm{C} / \mathrm{min}$. The mass spectra were recorded from 50 to $500(\mathrm{~m} / \mathrm{z})$, operating in exposure index mode at $70 \mathrm{eV}$. The volatile compounds were determined by comparing their mass spectra with NIST MS library V 2.0.

\section{Statistical analysis}

To confirm the reproducibility of the results, extraction experiments were replicated three times. The data was statistically analyzed using 20.0 SPSS software (IBM Corporation, Armonk, NY). The means \pm standard deviations were reported in the results.

\section{Results and discussion}

\section{Scanning electron microscopy (SEM)}

To observe the surface morphology of the cellulosic polysaccharides. The four isolated cellulosic fractions and the single un-roasted sample were characterized using SEM (Figure 1), which indicated rough surface morphology different from the images of the cellulose fibers reported in other studies (Ibrahim et al., 2010; Li et al., 2016; Song et al., 2015;). This was attributed to the residual non-cellulose compounds such as relatively high amounts of ash and hemicelluloses (Adel et al., 2011; Wang et al., 2010). As seen in the images of cellulosic polysaccharides from roasted sesame hulls, the C160, C180, C200, and C220 fractions showed irregular dispersed globular fragments, which may be due to the degradation of cellulosic compounds, as can be proved by the sugar analysis and the NMR analyses below.

\section{Yields and sugar components}

The objective of the investigation was to study the products of the degradation of cellulosic polysaccharides in the sesame hull cell wall during roasting. Delignification before extracting cellulosic polysaccharides can significantly improve the isolation of non-cellulosic 


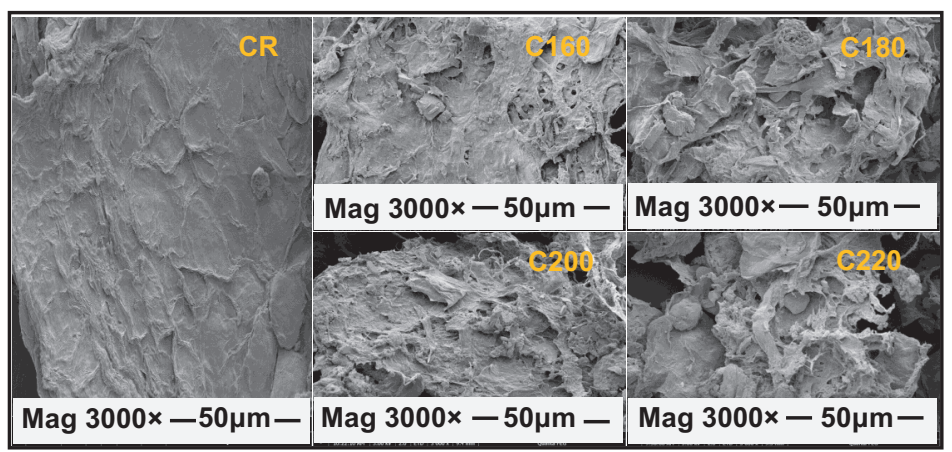

Figure 1. SEM images of the cellulosic polysaccharides isolated from the sesame hulls before and after roasting at various temperatures.

polysaccharide components and therefore result in the cellulosic polymers having high purity, the sesame hulls were not first delignified in this case to obtain more information about the products of the degradation of cellulosic polysaccharides in the cell wall. Therefore, in the present investigation, the un-roasted sesame hull and roasted sesame hulls at the temperatures of 160, 180, 200, and $220^{\circ} \mathrm{C}$ were treated directly with $4 \% \mathrm{NaOH}$ for $5 \mathrm{~h}$ at $50{ }^{\circ} \mathrm{C}$ to remove the hemicelluloses; yields were $57.1,57$, $57.6,61.6$, and $70.2 \%$, respectively, as shown in Table 1. Since roasting at high temperatures resulted in the degradation of the major component of the hemicelluloses, the residual insoluble fraction after post-treatment with alkali contained cellulose predominantly with minor quantities of hemicelluloses (Liu et al., 2020). For example, an increase in roasting temperature from 160 to 220 ${ }^{\circ} \mathrm{C}$ resulted in an increase of cellulosic polymers from 57.1 to $70.2 \%$.

Glucose was dominant in all fractions, derived mainly from cellulose. However, the fractions still contained $13-25 \%$ of non-cellulosic components: rhamnose (0.57$1.07 \%)$, arabinose (1.99-3.60\%), galactose (1.89-2.58\%), xylose (3.55-5.33\%), mannose (2.65-3.29\%), galacturonic (0.86-11.34\%), and glucuronic acid (0.16-0.65\%). Similar to the one reported in previous studies (Sun et al., 2013b; Liu et al., 2006), indicating roasting increased the relative amount of glucose in the cellulosic polysaccharides.
In contrast, the amounts of hemicelluloses in the cellulosic polysaccharides ( $24.78 \%$ for CR) isolated from the raw sesame hull dramatically decreased to $13.07 \%$ in the cellulosic polysaccharide (C220 fraction) indicating, that hemicelluloses, preferentially degraded during roasting and becomes soluble post-treating with $\mathrm{NaOH}$ solution. Besides, hemicellulose sugar components attached to cellulosic polymers depended on the roasting temperature, which indicated that the roasting degraded the sugars in the cell walls (Table 1). In the CR fraction isolated from the un-roasted sesame hull, galacturonic acid was the dominant sugar, comprising $11.34 \%$ of the total sugars, whereas it was almost nonexistent in the C220 fraction. Xylan and rhamnose (0.57-1.07\%) concentrations were also minimal post roasting treatment. This evidence proves the degradation of the hemicellulose components during roasting or post-treatment with alkali. Liu et al. (2020) showed that the major contributors to the caramelization and Maillard reaction during sesame hull roasting were the occurrence of galacturonic acid and xylose in the roasted samples, which supports our outcomes.

\section{FT-IR and NMR analyses}

Wide-angle X-ray diffraction (XRD), FT-IR, and CP/ MAS ${ }^{13} \mathrm{C}-\mathrm{NMR}$ are methods used for the structural

Table 1. Yields (based on the initial amount of dewaxed material) and sugar compositions of the cellulosic polysaccharides.

\begin{tabular}{|c|c|c|c|c|c|c|c|c|c|}
\hline \multirow[t]{2}{*}{ Samples } & \multirow[t]{2}{*}{ Yields (\%) } & \multicolumn{7}{|c|}{ Sugar composition (\%) } & \multirow[b]{2}{*}{ Glca } \\
\hline & & Rha & Ara & Gal & Glc & Xyl & Man & Gala & \\
\hline CR & $57.1 \pm 0.63$ & 1.07 & 1.99 & 1.89 & 75.22 & 5.33 & 2.99 & 11.34 & 0.16 \\
\hline C160 & $57.0 \pm 0.13$ & 0.72 & 3.06 & 2.58 & 78.22 & 4.67 & 3.07 & 7.02 & 0.65 \\
\hline C180 & $57.6 \pm 0.33$ & 0.62 & 3.60 & 2.41 & 82.86 & 4.20 & 3.29 & 2.40 & 0.62 \\
\hline C200 & $61.6 \pm 0.71$ & 0.57 & 3.44 & 2.32 & 84.51 & 4.13 & 3.07 & 1.45 & 0.50 \\
\hline C220 & $70.2 \pm 0.49$ & 0.65 & 2.83 & 2.12 & 86.93 & 3.55 & 2.65 & 0.86 & 0.41 \\
\hline
\end{tabular}

Rha, rhamnose; Ara, arabinose; Gal, galactose; Glc, glucose; Xyl, xylose; Man, mannose; Gala, galacturonic acid; Glca, glucuronic acid. 
characterization of crystalline cellulose and XRD analysis gives the most direct crystalline structure and quantitative information. But this study used FT-IR and CP/MAS ${ }^{13} \mathrm{C}$-NMR as XRD could not be used to obtain structural information of the cellulosic polysaccharides isolated from sesame hulls because the strong mineral signal in the XRD spectra of the cellulosic polymer resulted in indetectable crystalline information.

The FT-IR spectra of the cellulosic polysaccharides isolated from un-roasted and roasted sesame hulls are presented in Figure 2(A). The similar intensities of the absorption peaks suggested minimal differences in the cellulosic polysaccharides isolated from un-roasted and roasted sesame hulls. The absorption bands from 3600 to $2800 \mathrm{~cm}^{-1}$ is the result of the stretching of $\mathrm{C}-\mathrm{H}$ and $-\mathrm{OH}$ groups and that around $1630 \mathrm{~cm}^{-1}$ corresponds to free carboxyl groups, indicating the presence of uronic acid in the cellulosic polysaccharides (Sun et al., 2013), which is consistent with the sugar composition analysis as shown in Table 1 . In general, a peak at approximately $1730 \mathrm{~cm}^{-1}$ is an indication of esterification degree for uronic acid, which was absent in the spectra (Nep et al., 2016). The absorption region below $1500 \mathrm{~cm}^{-1}$ is attributed to deformation of the internal coordinates of the anhydroglucopyranose units, including the $\mathrm{C}-\mathrm{O}-\mathrm{C}, \mathrm{C}-\mathrm{H}, \mathrm{C}-\mathrm{O}$ units, and $\beta$-glycosidic linkages (Li et al., 2016); which showed no significant differences in this study.

$\mathrm{CP} / \mathrm{MAS}{ }^{13} \mathrm{C}$-NMR spectroscopy is useful for examining the structural changes in cellulose subjected to degradation (Sun et al., 2004). Therefore, the CP/MAS ${ }^{13} \mathrm{C}-\mathrm{NMR}$ spectra of the five fractions isolated from the sesame hulls before and after roasting were investigated (Figure 2(B)) according to the previous studies (Martins et al., 2005; Sun et al., 2004; Wang et al., 2017;). It can be observed from Figure 2(B) that the signals appearing between 60 and $110 \mathrm{ppm}$ were from cellulose carbons. The C6 signal was seen to split into two small peaks near 62.4 (amorphous) and 65.4 (crystalline) ppm. Signals from 70-80 $\mathrm{ppm}$ are attribute to $\mathrm{C} 2, \mathrm{C} 3$, and $\mathrm{C} 5$, which are not linked by glycoside bonds. The signal peaks of $80-90 \mathrm{ppm}$ and 98-110 ppm showed the chemical shift values of $\mathrm{C} 4$ and $\mathrm{C} 1$ atom, respectively. None of the carbon types disappeared after roasting, indicating no expressed modification in the cellulose chemical structure had occurred. Both amorphous and crystalline structures exist in cellulosic polymers. It has been proved that the cohesive energy density of amorphous cellulose is lower than that of crystalline cellulose (Mazeau and Heux, 2003), indicating the quick degradation of the former. The signal peaks at 89.2 and 84.4 ppm represented crystalline-and amorphous $\mathrm{C} 4$, respectively. The ratio values of crystalline-and total $\mathrm{C} 4$ peak areas were calculated to reveal the changes of CrI during roasting (see Figure 2(B); Zhao et al., 2006). When the roasting temperature was low (160 $\left.{ }^{\circ} \mathrm{C}\right)$, the $\mathrm{CrI}$ decreased slightly. As the roasting temperature rose to $180{ }^{\circ} \mathrm{C}$, it decreased sharply. It is worth noting that there was first a rise in $\mathrm{CrI}$ as the temperature rose from 180 to $200{ }^{\circ} \mathrm{C}$, and declined as the temperature further increased to $220{ }^{\circ} \mathrm{C}$. The increase of CrI, when the temperature rose from 180to $200{ }^{\circ} \mathrm{C}$, could be explained by the degradation of amorphous cellulose and other amorphous materials such as hemicelluloses as they have a relatively lower degradation temperature than cellulose (Yang et al., 2007). Basch and Lewin (1973) reported that amorphous cellulose has weaker thermal stability than crystalline cellulose and the CrI changes result from competitive degradation of crystalline cellulose and amorphous cellulose. So, when the roasting temperature increased to $220{ }^{\circ} \mathrm{C}$, the crystalline cellulose was converted into an amorphous form, leading to a slight decrease in the CrI. High temperature can significantly affect the structural properties of cellulose in the cell wall. In this study, the degradation of amorphous cellulose was observed post roasting. Hence, the contribution of the degraded products to the caramelization and Maillard reaction was evident.

\section{Thermal gravimetric analysis (TGA)}

TGA measures the mass loss due to the charring or volatilization of the components of a sample. This loss is monitored as a function of temperature. TGA and differential analysis (DTG) of the cellulosic polysaccharides isolated from un-roasted and roasted sesame hulls are presented in Figure 3. The combustion of cellulosic polysaccharides took place in four steps (Figure 3(A)). The initial shoulder peak at around $175^{\circ} \mathrm{C}$ mainly ascribed to the removal of free-and bound water (Wang et al., 2016; Yang et al., 2018). The second degradation peak (180 to $370{ }^{\circ} \mathrm{C}$ ) showed the thermal depolymerization of residual hemicelluloses. The results obtained were in agreement with the results from sugar composition analysis. An extensive rate of mass loss was observed at around $352{ }^{\circ} \mathrm{C}$. Comparing the values of these mass losses showed that the CR and C160 fractions had lower thermal stability than other fractions, which denoted higher amounts of residual hemicelluloses. At the temperature of $370{ }^{\circ} \mathrm{C}$, the highest residue yield was recorded for $\mathrm{C} 220$, which implied that $\mathrm{C} 220$ had the most thermal stability among the five fractions, due to the presence of the lowest residual hemicelluloses. The third degradation peak (370 to $496{ }^{\circ} \mathrm{C}$ ) inferred thermal depolymerization of cellulose. The thermal stability of cellulosic polymer is due to the repeated interlinking of the intermolecular and intramolecular hydrogen bonds (Wang et al., 2009). The thermal destruction of cellulosic polymer would cause cavities to form inside each microfibril. With the temperature increase, these microfibrils softened, and the cavities began to aggregate into networks of pores; the degraded 
(A)

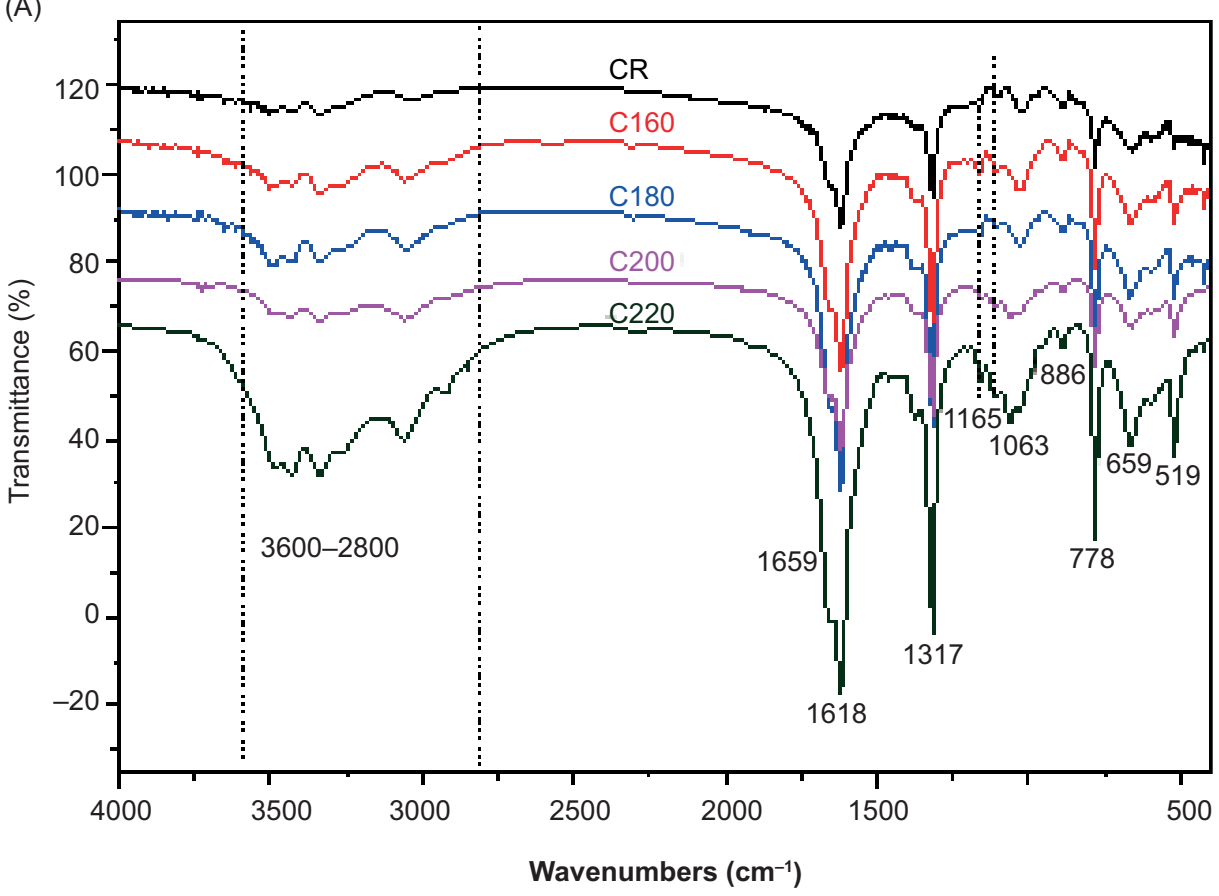

(B)

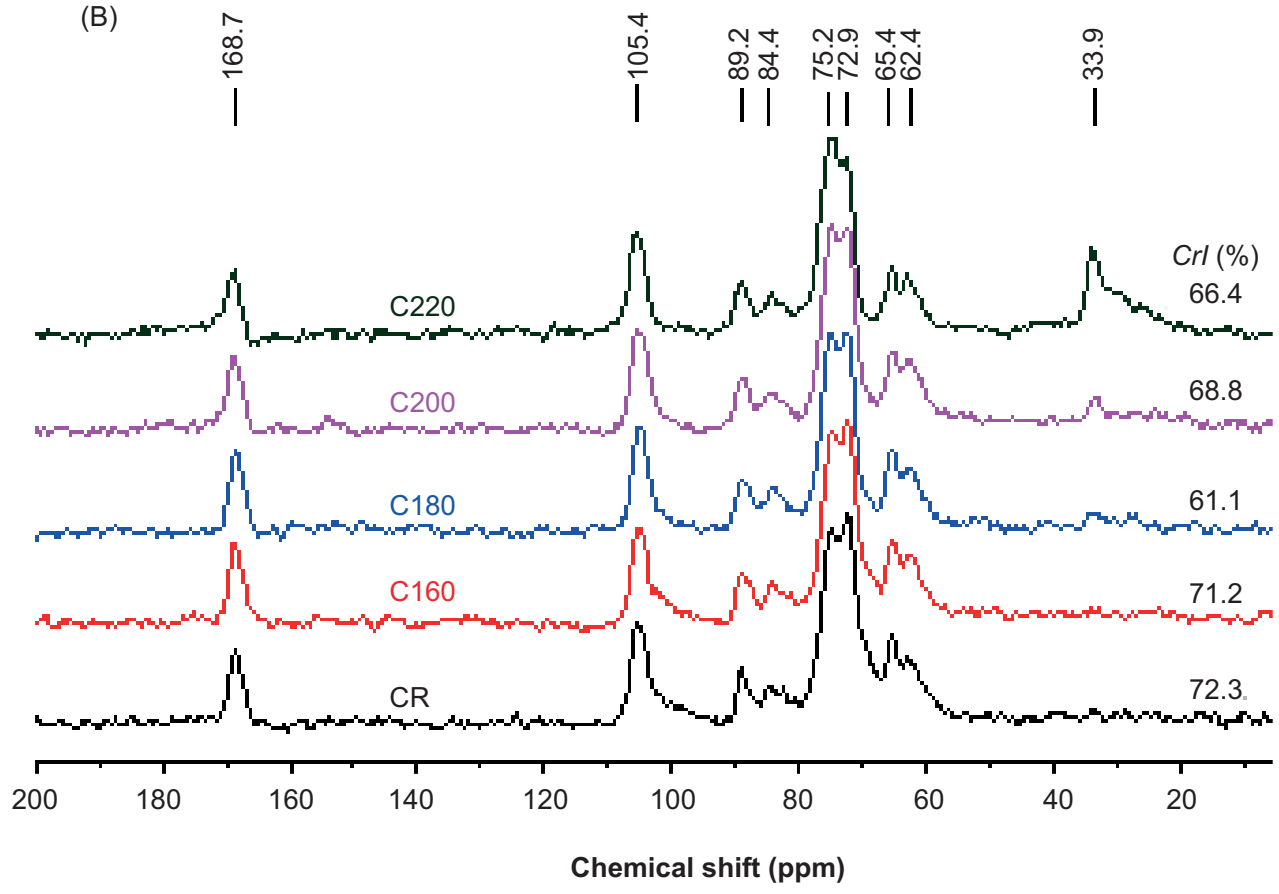

Figure 2. (A) FT-IR spectra and (B) CP/MAS ${ }^{13} \mathrm{C}$-NMR spectra of sesame hull cellulosic polysaccharides.

products exited the cellulose matrix, leading to the mass loss (Mamleev et al., 2007). From Figure 3(A), cellulosic polymer degradation could be divided into two stages. The first stage is mainly due to the amorphous form in the temperature ranging from 370 to $450{ }^{\circ} \mathrm{C}$. The slight weight loss was caused by the elimination of thermally unstable functional groups, which enhanced volatilization and simplified the cellulose structure, corresponding to the rise of $\mathrm{CrI}$ as aforementioned. The second stage is attributed to the degradation of crystalline cellulose into the amorphous form. Resulting in reduced thermal stability and excessive weight loss (Wang et al., 2017). The 

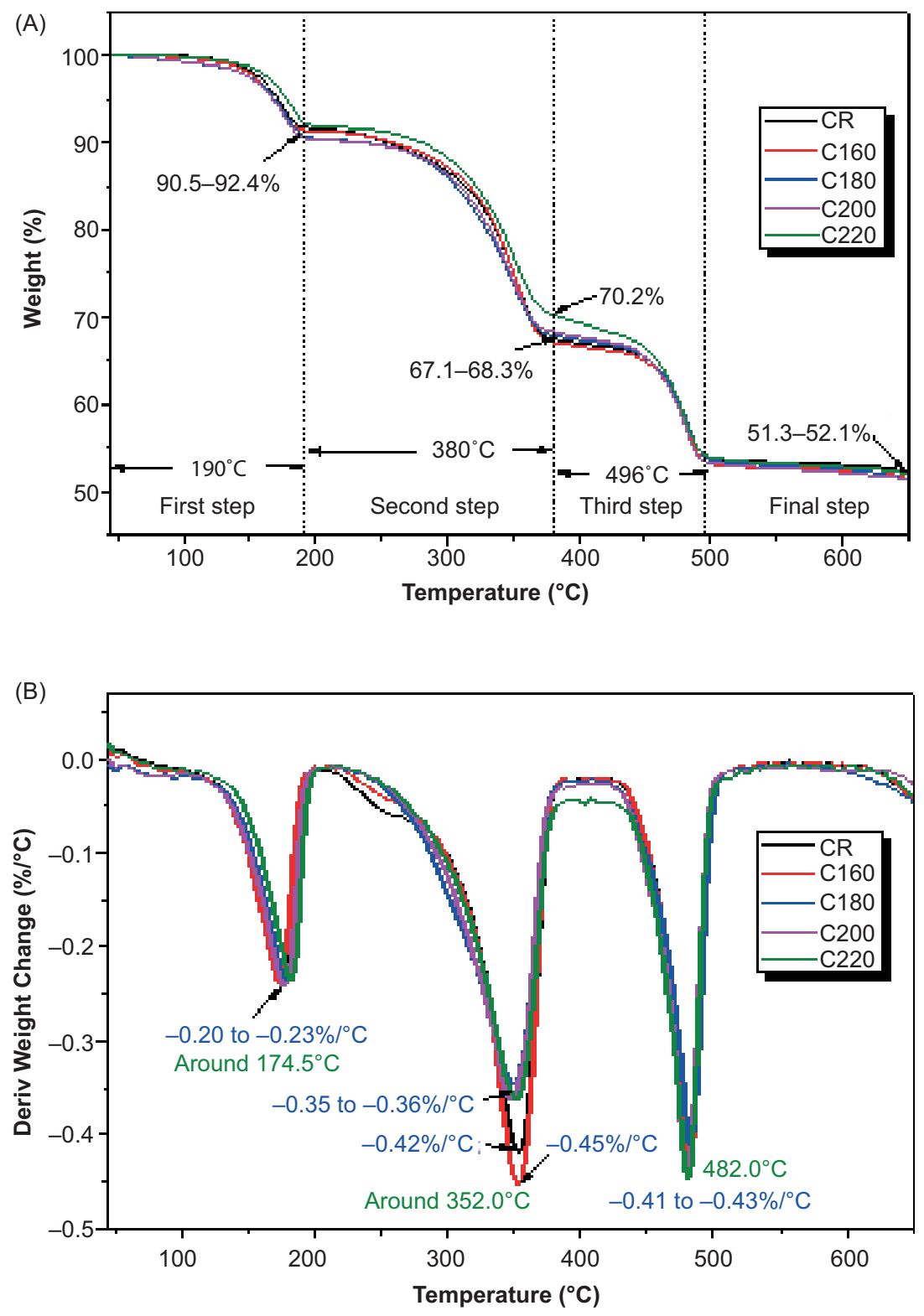

Figure 3. (A) TGA and (B) DTG curves of the cellulosic polysaccharides

cellulosic polymers isolated from sesame hulls had high residue yields of above 50\% (Figure 3(A)), presumably due to the relatively high amounts of minerals in sesame hulls (Elleuch et al., 2007).

\section{Py-GC/MS analysis of the cellulosic polysaccharides}

Py-GC/MS was used to characterize and verify the actual decomposition products of the cellulosic polysaccharides. The isolated polysaccharides from unroasted sesame hull were heated at 180, 200, and $220{ }^{\circ} \mathrm{C}$ for $30 \mathrm{~min}$, and then the volatiles was detected by GC/MS. No organic volatiles was detected by GC/MS when the temperatures were lower than $200^{\circ} \mathrm{C}$, indicating nil cellulose pyrolysis. The cellulosic polysaccharide obtained by $\mathrm{Py}-\mathrm{GC} / \mathrm{MS}$ is presented in Figure $\mathrm{S} 1$ and the identified compounds assigned to each of the peaks and corresponding structures are exhibited in Table S1.

The products derived from cellulosic polysaccharide pyrolysis were classified as alkanes, aldehydes, ketones, esters, methyl isocyanide, trichloromethane, and dimethyl sulfoxide based on the functional groups that were the outcome of one of the following processes: ring-opening, cleavage of $\mathrm{C}-\mathrm{C}$ bonds, decarbonylation, and dehydration (Shi et al., 2019) are shown in Figure 4. Based on the peak area (\%) results, acetic acid had the maximum yield among the derived products, reaching $28.3 \%$ of total 
(A)

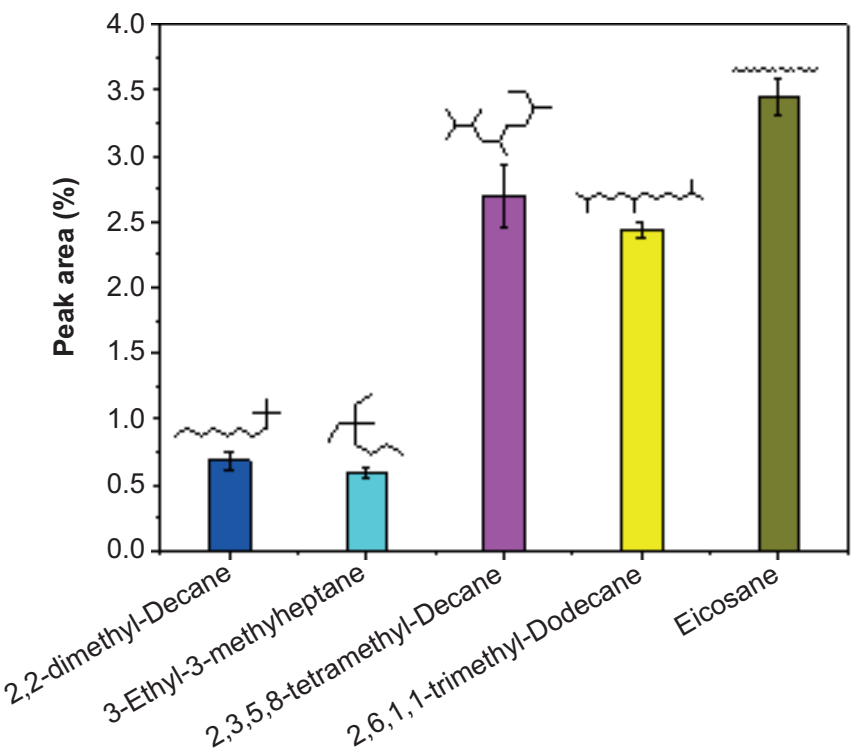

(C)

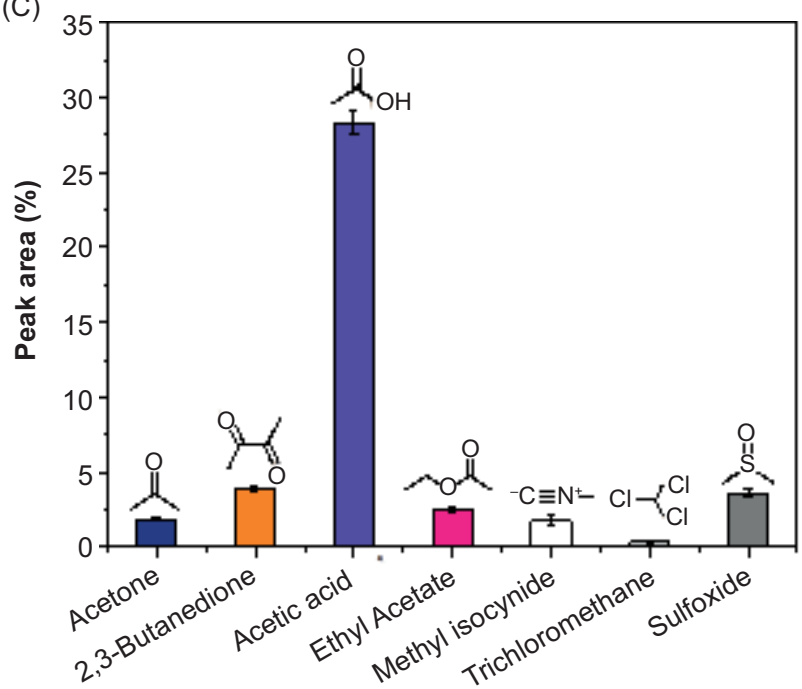

(B)
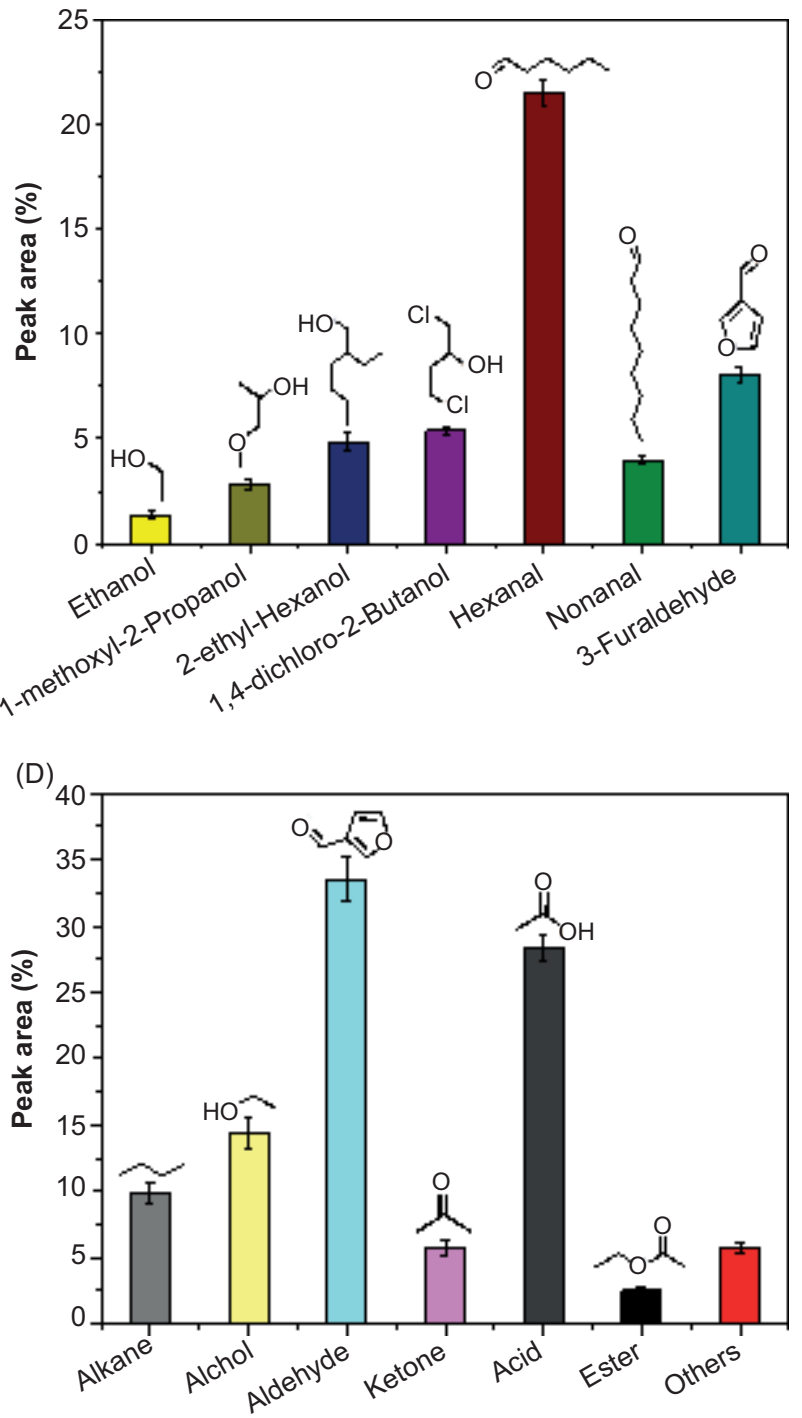

Figure 4. Cellulose pyrolysis products types and yields of Py-GC/MS: (A) alkanes, (B) alcohols and aldehydes, (C) acids, esters, and remaining compounds, and (D) total types and yields of the various compositions.

product contents. Acetic acid production occurs either ways: (1) Primary elimination of active O-acetyl groups linked to the cellulosic polysaccharides; (2) The ketene of galacturonic acid fragments after the elimination of O-methyl and carbonyl groups (Shen et al., 2010). The latter chemical formation pathway for acetic acid may have occurred in this study. A significant reduction in galacturonic acid units was observed with increases roasting temperatures. Acids can play a significant role in chemical reactions because they can donate protons which promote chemical reactions in the sesame hull roasting process. Furfural (3-furaldehyde) is a typical ring-containing product of the pyrolysis of hemicelluloses and cellulosic polysaccharides. One probable mechanism by which 3-furaldehyde is produced involves the cleavage of the hemiacetal bond of the depolymerized pentose units that are attached to the cellulosic polysaccharides, followed by the dehydration of hydroxyl groups (Shen et al., 2010; Wang et al., 2015). According to the analysis of the volatile compounds from pyrolysis of the cellulosic polysaccharides, those volatile compounds may be significant contributors to the Maillard reaction and caramelization that occur during the roasting of sesame seeds.

\section{Degradation mechanisms of the cellulosic polysaccharides during roasting process}

The cell wall components of sesame hulls are cellulose, hemicelluloses, and traces of lignin. The depolymerization 
temperature of Hemicelluloses is 180 to $350{ }^{\circ} \mathrm{C}$, and cellulose is $300-430{ }^{\circ} \mathrm{C}$ temperature (Miettinen et al., 2017). The sesame seeds in this study were roasted below 220 ${ }^{\circ} \mathrm{C}$. Therefore, the degradation products from hemicelluloses were the main contributors to the caramelization and Maillard reaction that occur during roasting. The FT-IR and CP/MAS ${ }^{13} \mathrm{C}-\mathrm{NMR}$ tests indicated that the roasting temperatures used in this study did not change the crystalline structure of cellulose nor of linkages between these sugar units. This study results indicated that the amorphous cellulose partly degraded during roasting, although the crystalline cellulose did not. The sugar analysis showed that roasting markedly changed the sugar distributions in the cellulosic polysaccharides. In summary, galacturonic acid, xylose, and rhamnose units attached to cellulose were more easily degraded than other sugar units, which agreed with the study of Liu et al. (2020). The degradation compounds, such as acetic acid and 3-furaldehyde, identified by Py-GC/MS experiment, were likely significant contributors to caramelization and the Maillard reaction in sesame seed roasting.

\section{Conclusion}

Our results outcomes showed that the hemicellulose sugars could be easily degraded than other sugars. During roasting, the crystalline structure and linkages of these sugar units in cellulose did not obviously break down; but partly degraded amorphous cellulose to various volatile compounds, such as acetic acid and 3-furaldehyde, which were significant contributors to caramelization and the Maillard reaction in sesame seed roasting. This investigation helped elucidate the degradation mechanism of cellulose in the cell wall of sesame hulls on roasting.

\section{Funding}

The research was financially supported by the Natural Science Foundation of China (31801576) and the Modern Agro-industry Technology Research System (CARS14-1-29).

\section{References}

Adel, A.M., EI-wahab, Z.H.A., Ibrahim, A.A., and Al-Shemy, M.T., 2011. Characterization of microcrystalline cellulose prepared from lignocellulosic materials. Part II: physicochemical properties. Carbohydrate Polymers 83: 676-687. https://doi. org/10.1016/j.carbpol.2010.08.039

Basch, A. and Lewin, M., 1973. The influence of fine structure on the pyrolysis of cellulose. I. Vacuum pyrolysis. Journal of Polymer Science Polymer Chemistry 11: 3071-3093. https://doi. org/10.1002/pol.1974.170120919
Brands, C.M.J. and Van Boekel, M.A.J.S., 2001. Reactions of monosaccharides during heating of sugar-casein systems: building of a reaction network model. Journal of Agricultural \& Food Chemistry 49: 4667-4675. https://doi.org/10.1021/jf001430b

Coghe, S., Gheeraert, B., Michiels. A., and Delvaux, F.R., 2012. Development of Maillard reaction related characteristics during malt roasting. Journal of the Institute of Brewing 112:148-156. https://doi.org/10.1002/j.2050-0416.2006.tb00244.x

Elleuch, M., Besbes, S., Roiseux, O., Blecker, C., and Attia, H., 2007. Quality characteristics of sesame seeds and by-products. Food Chemistry 103: 641-650. https://doi.org/10.1016/j. foodchem.2006.09.008

Farran, M.T., Uwayjan, M.G., Miski, A.M.A., Akhdar, N.M., and Ashkarian, V.M., 2000. Performance of broilers and layers fen graded levels of sesame hull. Journal of Applied Poultry Research 9: 453-459. https://doi.org/10.1093/japr/9.4.453

Hwang, I.G., Kim, H.Y., Woo, K.S., Lee, J., and Jeong, H.S., 2011. Biological activities of Maillard reaction products (MRPs) in a sugar-amino acid model system. Food Chemistry 126: 221-227. https://doi.org/10.1016/j.foodchem.2010.10.103

Ibrahim, M.M., Agblevor, F.A., and El-Zawawy, W.K., 2010. Isolation and characterization of cellulose and lignin from steam-exploded lignocellulosic biomass. Bioresources 5: 397-418. https://doi.org/10.1007/s00226-009-0268-z

Kahyaoglu, T. and Kaya, S., 2006. Determination of optimum processing conditions for hot-air roasting of hulled sesame seeds using response surface methodology. Journal of the Science of Food and Agriculture 86: 1452-1459. https://doi.org/10.1002/ jsfa.2509

Lee, S.W., Jeung, M.K., Park, M.H., Lee, S.Y., and Lee, J.H., 2010. Effects of roasting conditions of sesame seeds on the oxidative stability of pressed oil during thermal oxidation. Food Chemistry 118: 681-685. https://doi.org/10.1016/j.foodchem.2009.05.040

Liu, C.F., Ren. J.L., Xu, F., Liu, J.J., Sun, J.X., and Sun, R.C., 2006. Isolation and characterization of cellulose obtained from ultrasonic irradiated sugarcane bagasse. Journal of Agricultural \& Food Chemistry 54: 5742-5748. https://doi.org/10.1021/ jf060929o

Liu, H.M., Yao, Y.G., Yan, Y.Y., and Wang, X.D., 2020. Elucidation of the structure changes of sesame hull hemicelluloses during roasting process. International Journal of Biological Macromolecules 161: 1535-1544. https://doi.org/10.1016/j.ijbiomac.2020.07.287

Li, J.H., Zhang, S., Gao, B.Y., Yang, A.K., Wang, Z.H., Xia, Y.Z., et al., 2016. Characteristics and deoxy-liquefaction of cellulose extracted from cotton stalk. Fuel 166: 196-202. https://doi. org/10.1016/j.fuel.2015.10.115

Magorzata, W., Konrad, P.M., and Zieliński, H., 2016. Effect of roasting time of buckwheat groats on the formation of Maillard reaction products and antioxidant capacity. Food Chemistry 196: 355-358. https://doi.org/10.1016/j.foodchem.2015.09.064.

Matsuoka S., Kawamoto H., and Saka S., 2014. What is active cellulose in pyrolysis? An approach based on reactivity of cellulose reducing end. Journal of Analytical \& Applied Pyrolysis 106:138-146. https://doi.org/10.1016/j.jaap.2014.01.011

Martins, M.A., Forato, L.A., Mattoso, L.H.C., and Colnago, L.A., 2005. A solid state $13 \mathrm{C}$ high resolution NMR study of raw and 
chemically treated sisal fibers. Carbohydrate Polymers 340: 1-7. https://doi.org/10.1016/j.carbpol.2005.10.034

Mazeau, K. and Heux, L., 2003. Molecular dynamics simulations of bulk native crystalline and amorphous structures of cellulose. Journal of Physical Chemistry B 107: 2394-2403. https://doi. org/10.1021/jp0219395

Mamleev, V., Bourbigot, S., and Yvon, J., 2007. Kinetic analysis of the thermal decomposition of cellulose: the main step of mass loss. Journal Analytical \& Applied Pyrolysis 80: 151-165. https://doi. org/10.1016/j.jaap.2007.01.013

Miettinen, I., Kuittinen, S., Paasikallio, V., Mäkinen, M., Ari, P., and Janne, J., 2017. Characterization of fast pyrolysis oil from short-rotation willow by high-resolution Fourier transform ion cyclotron resonance mass spectrometry. Fuel 207: 189-197. https://doi.org/10.1016/j.fuel.2017.06.053

Nandi I., Sengupta A., and Ghosh M., 2018. Effects of dietary fibres extracted from defatted sesame husk, rice bran \& flaxseed on hypercholesteromic rats. Bioactive Carbohydrates \& Dietary Fibre 17: 1-6. https://doi.org/10.1016/j.bcdf.2018.12.002

Nep, E.I., Carnachan, S.M., Ngwuluka, N.C., Kontogiorgos, V., Morris, G.A., Sims, I.M., et al., 2016. Structural characterisation and rheological properties of a polysaccharide from sesame leaves (Sesamum radiatum Schumach. \& Thonn.). Carbohydrate Polymers 152: 541-547. https://doi.org/10.1016/j. carbpol.2016.07.036

Parker, J.K., 2015. Thermal generation of aroma. In. Parker, J.K., Elmore, J.S., and Methven, L., editors, Flavour development, analysis and perception in food and beverages. Cambridge: wood publishing. p.185. https://doi.org/10.1016/ b978-1-78242-103-0.00009-6

Sun, X.F., Sun, R.C., Fowler, P., and Baird, M.S., 2004. Isolation and characterisation of cellulose obtained by a two-stage treatment with organosolv and cyanamide activated hydrogen peroxide from wheat straw. Carbohydrate Polymers 55: 379-391. https:// doi.org/10.1016/j.carbpol.2003.10.004

Sun, S.L., Wen, J.L., Ma, M.G., and Sun, R.C., 2013a. Successive alkali extraction and structural characterization of hemicelluloses from sweet sorghum stem. Carbohydrate Polymers 92: 2224-2231. https://doi.org/10.1016/j.carbpol.2012.11.098

Sun, Y.F., Yang, X.B., Lu, X.S., Wang, D.Y., and Zhao, Y., $2013 \mathrm{~b}$. Protective effects of Keemun black tea polysaccharides on acute carbon tetrachloride-caused oxidative hepatotoxicity in mice. Food \& Chemical Toxicology 58: 184-192. https://doi. org/10.1016/j.fct.2013.04.034

Shen, D.K., Gu, S., and Bridgwater, A.V., 2010. The thermal performance of the polysaccharides extracted from hardwood: Cellulose and hemicellulose. Carbohydrate Polymers 82: 39-45. https://doi.org/10.1016/j.carbpol.2010.04.018
Shi, Z.J., Zhang, R.Y., Sun, J., Xie, X.A., and Liu, H.M., 2019. Understanding the mechanism of cornstalk liquefaction in water/ethanol mixtures through Py-GC/MS analysis of the solid residues. Industrial Crops \& Products 130: 292-300. https://doi. org/10.1016/j.indcrop.2019.01.002

Song, Y.L., Zhang, J.Z., Zhang, X., and Tan, T.W., 2015. The correlation between cellulose allomorphs (I and II) and conversion after removal of hemicellulose and lignin of lignocellulose. Bioresource Technology 193: 164-170. https://doi.org/10.1016/j. biortech.2015.06.084

Wang, S.R., Dai, G.G., Ru, B., Zhao, Y., Wang, X.L., Xiao, G., and Luo, Z.Y., 2017. Influence of torrefaction on the characteristics and pyrolysis behavior of cellulose. Energy 120: 864-871. https://doi.org/10.1016/j.energy.2016.11.135

Wang, W.J., Ma, X.B., Jiang, P., Hu, L.L., Zhi, J.Z., Chen, J.L., et al., 2016. Characterization of pectin from grapefruit peel: a comparison of ultrasound-assisted and conventional heating extractions. Food Hydrocolloids 61: 730-739. https://doi. org/10.1016/j.foodhyd.2016.06.019

Wang, K., Jiang, J.X., Xu, F., and Sun, R.C., 2009. Influence of steaming explosion time on the physic-chemical properties of cellulose from Lespedeza stalks (Lespedeza crytobotrya). Bioresource Technology 100: 5288-5294. https://doi.org/10.1016/j. biortech.2009.05.019

Wang, S., Ru, B., Lin, H.Z., and Sun, W.X., 2015. Pyrolysis behaviors of four O-acetyl-preserved hemicelluloses isolated from hardwoods and softwoods. Fuel 150: 243-251. https://doi. org/10.1016/j.fuel.2015.02.045

Wang, D., Shang, S.B., Song, Z.Q., and Lee. M.K., 2010. Evaluation of microcrystalline cellulose prepared from kenaf fibers. Journal of Industrial and Engineering Chemistry 16: 152-156. https:// doi.org/10.1016/j.jiec.2010.01.003

Yang, H.P., Yan, R., Chen, H.P., Lee, D.H., and Zheng, C.G., 2007. Characteristics of hemicellulose, cellulose and lignin pyrolysis. Fuel 86:1781-1788. https://doi.org/10.1016/j.fuel.2006.12.013

Yang, X., Nisar, T., Liang, D., Hou, Y.J., Sun, L.J., and Guo, Y.R., 2018. Low methoxylpectingelation under alkaline conditions and its rheological properties: using $\mathrm{NaOH}$ as a $\mathrm{pH}$ regulator. Food Hydrocolloids 79: 560-571. https://doi.org/10.1016/j. foodhyd.2017.12.006

Zhang, X.C., Chen, F., and Wang, M.F., 2013. Impacts of selected dietary polyphenols on caramelization in model systems. Food Chemistry 141: 3451-3458. https://doi.org/10.1016/j. foodchem.2013.06.053

Zhao, H., Kwak, J.H., Wang, Y., Franz, J.A., White, J.M., and Holladay, J.E., 2006. Effects of crystallinity on dilute acid hydrolysis of cellulose by cellulose ball-milling study. Energy \& Fuels 20: 807-811. https://doi.org/10.1021/ef050319a 


\section{Supplementary data}

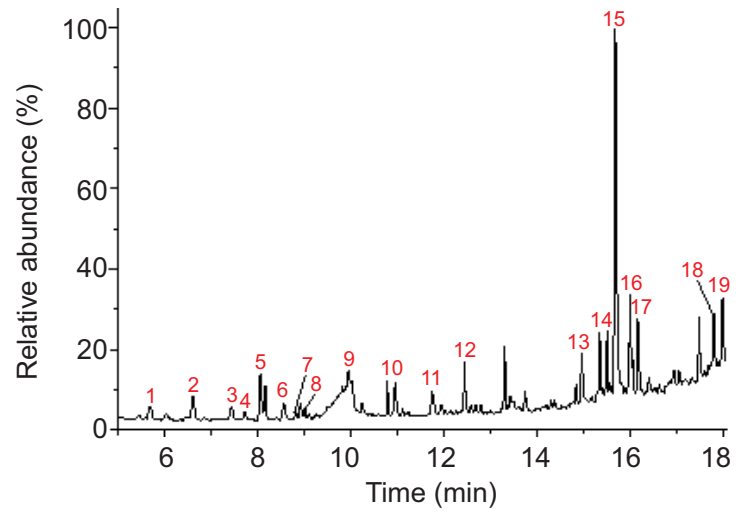

Figure S1. Total ion chromatograms of cellulosic polysaccharide by Py-GC/MS.

Table S1. Identification and relative content (\%) of the cellulose pyrolysis products by Py-GC/MS analysis

\begin{tabular}{|c|c|c|c|c|c|}
\hline & No. & Compounds & Structure & Content (\%) & Peak area \\
\hline \multirow[t]{5}{*}{ Alkane } & 4 & 2,2-dimethyl-Decane & & $0.675 \pm 0.071$ & 11196 \\
\hline & 8 & 3-Ethyl-3-methylheptane & & $0.586 \pm 0.035$ & 9716 \\
\hline & 11 & 2,3,5,8-tetramethyl-Decane & & $2.693 \pm 0.241$ & 44667 \\
\hline & 12 & 2,6,11-trimethyl- Dodecane & & $2.437 \pm 0.058$ & 40422 \\
\hline & 14 & Eicosane & & $3.448 \pm 0.137$ & 57181 \\
\hline \multirow[t]{4}{*}{ Alcohol } & 3 & Ethanol & & $1.365 \pm 0.224$ & 22643 \\
\hline & 10 & 1-methoxy-2-Propanol & & $2.796 \pm 0.251$ & 46366 \\
\hline & 17 & 2-ethyl-1-Hexanol & & $4.841 \pm 0.459$ & 80292 \\
\hline & 19 & 1,4-dichloro-2-Butanol & & $5.366 \pm 0.227$ & 88991 \\
\hline \multirow[t]{3}{*}{ Aldehyde } & 9 & Hexanal & & $21.487 \pm 0.662$ & 356361 \\
\hline & 13 & Nonanal & & $3.989 \pm 0.182$ & 66150 \\
\hline & 16 & 3-Furaldehyde & & $8.029 \pm 0.387$ & 133160 \\
\hline
\end{tabular}


Yao Y-G et al.

Table S1. Continued

\begin{tabular}{|c|c|c|c|c|c|}
\hline & NO. & Compounds & Structure & Content (\%) & Peak area \\
\hline \multirow[t]{2}{*}{ Ketone } & 1 & Acetone & & $1.879 \pm 0.117$ & 31156 \\
\hline & 5 & 2,3-Butanedione & $\mathrm{O}$ & $3.889 \pm 0.182$ & 64501 \\
\hline Acid & 15 & Acetic acid & & $28.311 \pm 0.81$ & 469523 \\
\hline Ester & 2 & Ethyl Acetate & & $2.532 \pm 0.184$ & 41991 \\
\hline \multirow[t]{3}{*}{ Others } & 6 & Methyl isocyanide & & $1.758 \pm 0.329$ & 29158 \\
\hline & 7 & Trichloromethane & & $0.363 \pm 0.049$ & 6014 \\
\hline & 18 & Dimethyl Sulfoxide & & $3.556 \pm 0.267$ & 58979 \\
\hline
\end{tabular}

